\title{
Penyuluhan Pemanfaatan Limbah Serbuk Gergajian Sebagai Bahan Papan Komposit
}

\author{
Salman Salman ${ }^{1}$, Emmy Dyah Sulistyowati ${ }^{2}$, I Made Adi Sayoga ${ }^{3}$, Agus Dwi Chatur ${ }^{4}$ \\ 1,2,3,4 Teknik Mesin, Fakults Teknik, Universitas Mataram \\ E-mail: ${ }^{1}$ salman@unram.ac.id, ${ }^{2}$ e.dyah@unram.ac.id, ${ }^{3}$ adis@unram.ac.id, \\ agus.dc@unram.ac.id
}

\begin{abstract}
Abstrak
Pengusaha pengolahan kayu perlu mengantisipasi kenaikan harga bahan baku kayu dengan mencari bahan baku alternatif. Salah satunya adalah papan komposit. Papan komposit menggunakan serbuk gergaji sebagai bahan utama komponen komposit. Di semua pabrik pengolahan kayu, para pengusaha meninggalkan tumpukan serbuk gergaji, terutama dari serutan dan gergajian.

Oleh karena itu perlu adanya pemanfaatan limbah serbuk gergaji menjadi bahan papan komposit melalui bakti sosial. Kegiatan dilakukan dengan membuat papan komposit dan memberikan penyuluhan langsung kepada mitra kerja terkait penggunaan serbuk gergaji dari pengolahan kayu. Hasilnya mitra kerja antusias dan menyambut baik gagasan tim pelaksana kegiatan pengabdian ini.
\end{abstract}

Kata kunci: papan komposit, serbuk gergaji, pengabdian masyarakat

\begin{abstract}
Wood processing entrepreneurs need to anticipate rising prices for wood raw materials by looking for alternative raw materials. One of them is a composite board. Composite boards use sawdust as the main ingredient of the composite components. In all wood processing plants, entrepreneurs leave piles of sawdust, especially from shavings and sawn.

Therefore, it is necessary to use sawdust waste into composite board material through social service. Activities carried out by making composite boards and providing direct counseling to partners regarding the use of sawdust from wood processing.
\end{abstract}

Keywords: composite board, sawdust, social service

\section{PENDAHULUAN}

Sektor industri mebel atau furniture adalah salah satu bentuk pengolahan kayu yang banyak diusahakan di (Nusa Tenggara Barat) NTB. Namun terjadi penurunan pertumbuhan produksi di bidang pengolahan kayu [1] disebabkan makin melonjaknya harga bahan baku kayu siap olah. Akibatnya harga-harga produk olahan kayu juga ikut naik [2]. Sejumlah kelompok usaha olahan kayu di Batu Ringgit, Kelurahan Karang Pule, Kotamadya Mataram, NTB, mengakui hal ini. Pengusaha-pengusaha tersebut.memproduksi sejumlah barang hasil olahan kayu seperti furnitur atau mebel, kayu, pintu, kusen dan jendela Alat-alat yang digunakan adalah alat manual sederhana dan semi modern yang menggunakan listrik seperti mesin bor, serut, gergaji listrik dan peralatan tukang kayu lainnya. Daya listrik yang tersedia di tempat usaha adalah 1300 watt. Daya ini masih kecil jika hendak menggunakan banyak alat-alat lisrik secara bersamaan.

Dalam hal manajemen masih menggunakan manajemen sederhana dalam pengolahan usaha olahan kayunya. Yaitu hanya membuat produk jika menerima pesanan. Hal ini 
dikarenakan keuntungan yang diperoleh dari pembutan produk dibagi bersama ke karyawan, karena modal sebagian besar dipakai untuk membeli bahan baku kayu dari luar kabupaten.

Permasalahan utama dari waktu ke waktu adalah harga-harga bahan baku yang makin naik, akibatnya harga produk juga ikut naik. Untuk 1 lemari misalnya ia membutuhkan waktu 3 minggu dengan untung yang sedikit yaitu Rp 150 ribu. Di lain pihak konsumen menuntut harga produk yang bagus dan murah. Bahan baku diperoleh dari Kabupaten Lombok Tengah dan Timur, NTB. Terdiri dari berbagai jenis kayu. Kayu-kayu tersebut sudah dalam bentuk papan dan balok berbagai ukuran.. Harga papan $3 \mathrm{~cm}$ per ton di Mataram adalah Rp 2,5 juta. Harga ini belum termasuk kayu bersih hasil ketam. Sedangkan untuk kayu balok, broti serta papan mencapai Rp 3 juta per ton. Mahalnya harga kayu ini membuat pengrajin mebel mematok harga yang lebih tinggi lagi. Dalam pengolahan bahan baku dari kayu tersebut mitra menyisakan tumpukan serbuk kayu terutama dari hasil serutan dan gergajian. Setiap hari bisa terdapat 20 karung serbuk kayu. Mitra menjual limbah serbuk itu ke pengepul seharga Rp 2000 per karung untuk dijadikan pupuk. Mitra belum berpikir untuk memanfaatkan limbah serbuk kayu tersebut karena belum ada ide.

Salah satu bentuk pemanfaatan serbuk kayu yang cocok adalah dengan mengolahnya menjadi bahan baku produk. Bahan serbuk kayu tersebut bisa didaur ulang menjadi papan atau balok komposit yang memiliki kekuatan yang sama dengan papan asli. Dengan demikian akan mengurangi ketergantungan pada papan atau balok dari kayu asli untuk dimanfaatkan sebagai bahan baku mebel dan produk olahan kayu lainnya. Upaya pembuatan bahan baku alternatif seperti papan komposit perlu dilakukan. Dengan demikian pengusaha mebel tidak hanya mengandalkan bahan baku kayu mentah yang kian waktu makin langka dan melonjak harganya (lihat Gambar 1).

Dengan variasi bahan baku produk dari papan komposit ini maka akan menghasilkan produk yang unik apalagi disertai desain yang mengikuti selera konsumen. Desain bisa dilakukan karena bentuk kayu komposit bisa dibuat sesuai dengan bentuk cetakan. Dengan demikian pengusaha tak perlu menggunakan alat pertukangan yang biasanya membutuhkan daya listrik yang besar.

Desain papan kayu bisa disesuaikan dengan bentuk produk yang diinginkan antara lain produk berukir, bertekstur, dan bentuk permukaan mebel pada umumnya.

Karena itulah menyikapi masalah melonjaknya harga bahan baku kayu mentah dan variasi desain yang monoton maka perlu diadakan usaha pengadaan papan alternatif dari sisa serbuk kayu menjadi bahan komposit melalui kegiatan pengabdian masyarakat. Komponen penyusun papan komposit ini adalah resin sebagai matriks, serbuk kayu sebagai isian dan serat batang pisang sebagai penguat. Serbuk kayu tak perlu dibeli, mudah diperoleh di lokasi mitra. Kegiatan ini merangkaikan pembuatan papan komposit dengan penyuluhan depan mitra secara langsung.

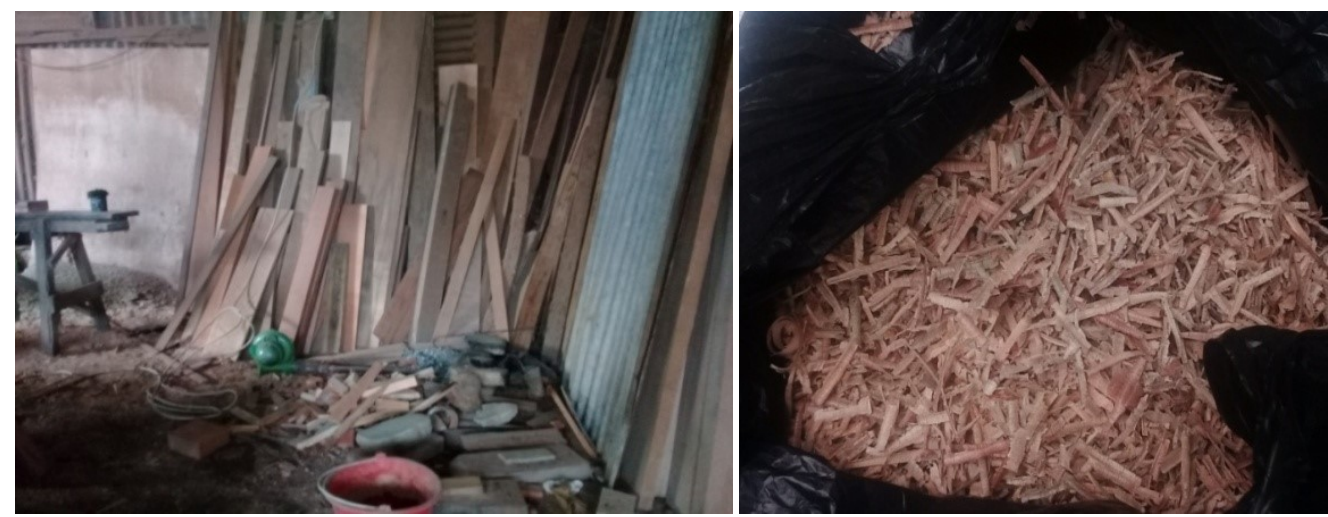

Gambar 1. Sejumlah ukuran papan dan balok di tempat mitra dan Serbuk kayu sisa gergajian. 


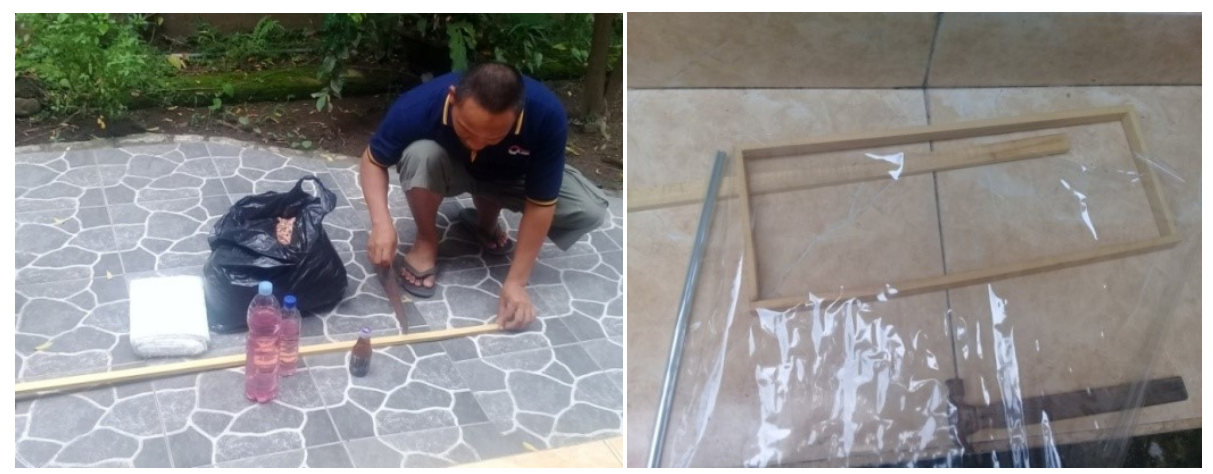

Gambar 2 Pembuatan cetakan.

\section{METODE}

Pendekatan yang dilakukan untuk penyelesaian permasalahan di atas dilakukan dengan tahapan sebagai berikut:

\subsection{Observasi}

Tim pelaksana pengabdian telah melakukan observasi ke sejumlah pelaku usaha pengolahan kayu di Batu Ringgit, Kelurahan Karang Pule, Kotamadya Mataram, NTB. Di lingkungan tersebut terdapat sejumlah pelaku usaha yang menggeluti usaha pengolahan kayu menjadi produk tertentu. Tim pengabdian masyarakat kemudian menentukan Azmi sebagai mitra dengan pertimbangan, jumlah karyawan, luas area aktivitas kerja dan limbah sisa hasil olahan kayu yang menumpuk.

Dalam observasi tersebut mitra menyetujui diadakannya kegiatan penyuluhan papan komposit di tempat mitra.

\subsection{Penyiapan Bahan dan Alat}

Bahan-bahan yang dibutuhkan dalam pembuatan papan komposit adalah terdiri dari bahan pembuatan cetakan dan bahan untuk kompositnya sendiri. Adapun bahan utama untuk cetakannya adalah perekat yang digunakan yaitu perekat pengeras (hardener) yang digunakan adalah NHC1 (Amonium Chlorida) 2\%, resin poliester tak jenuh (campuran oligomer poliester tak jenuh dan monomer stiren) dengan nama komersial Yucalac Ripe 2250, katalisator MEKPO, serbuk kayu, dan bahan pendukung lainnya [3] dan [4].

\subsection{Pembuatan Cetakan}

Cetakan dibuat dari papan dan lis kayu. Kayu lis dipotong menjadi ukuran $60 \mathrm{~cm}$ sebanyak 2 potong dan $20 \mathrm{~cm}$ sebanyak 2 potong juga. Selanjutnya papan alas cetakan dipotong sepanjang $60 \mathrm{~cm}$. Selanjutnya disatukan membentuk cetakan komposit [5].

\subsection{Pembuatan Komposit}

Lapisan alas cetakan dengan terpal seukuran $70 \mathrm{~cm}$ x $25 \mathrm{~cm}$ sebagai alas campuran agar campuran nantinya tak melekat pada cetakan. Siapkan serbuk kayu sebanyak dua liter dan fiber glass dengan ukuran $18 \mathrm{~cm}$ x $55 \mathrm{~cm}$ sebanyak 3 lembar [6].

Resin atau epoxy sebanyak $500 \mathrm{ml}$ dicampur dengan hardener sebanyak $20 \mathrm{ml}$ atau setengah sendok teh. Selanjutnya diaduk selama 20 detik lalu dituangkan perlahan sebanyak 100 $\mathrm{ml}$ ke cetakan. Serbuk gergaji atau kayu dimasukkan ke cetakan secara merata di alas cetakan. Tuangkan kembali campuran resin sebanyak $100 \mathrm{ml}$ ke atas serbuk kayu tersebut. Ratakan menggunakan kapi. Selanjutnya letakkan fiber glass di atas serbuk kayu tersebut.

Kembali resin dituangkan sebanyak $50 \mathrm{ml}$. Ratakan resinnya di atas fiber. Lalu Tambahkan fiber kedua kembali di atas fiber yang pertama, lalu tuangkan lagi $50 \mathrm{ml}$ resin 
campuran. Setelah campuran rata letakkan fiber terakhir di atas resin yang rata tersebut tuangkan kembali kemudian resin sebanyak $50 \mathrm{ml}$, ratakan di atas fiber tersebut. Selanjutnya taburkan sisa serbuk kayu di atas resin tersebut ratakan menggunakan kapi yang bersih. Selanjutnya sisa resin campuran dituangkan di atas serbuk kayu. Ratakan dengan kapi sambil ditekan. Setelah semua bagian terisi dengan resin diamkan campuran cetakan di tempat yang teduh. Cetakan tidak disentuh sampai selama 24 jam [7].

\subsection{Penyuluhan}

Penyuluhan mengenai pemanfaatan limbah serbuk gergaji dilakukan di dua tempat yaitu di usaha pertukangan kayu milik Azmi dan Zainuddin, di Desa Batu Ringgit, Kelurahan Karang Pule, Kodya Mataram, NTB.

\section{HASIL DAN PEMBAHASAN}

Cetakan yang telah kering kemudian dilepas dengan cara mengangkat perlahan terpal; yang berada di pinggirnya sisi demi sisi. Jika agak sulit dipelas pukul-pukul cetakan ke arah bawah sambil diangkat sedikit agar cetakan terjatuh sendiri.

Hasil cetakan berupa papan komposit telah jadi dan siap digunakan sebagai papan pengganti papan konvensional dari bahan baku kayu seperti pada umumnya (lihat Gambar 3).

Menguntungkannya, di tempat mitra terdapat banyak tumpukan limbah serbuk kayu menjadi bahan penyusun utama papan komposit. Pembuatan kayu komposit dalam bentuk papan dan balok ini dimungkinkan karena di tempat usaha mitra terdapat tumpukan limbah olahan kayu dalam bentuk serbuk dan remahan kayu.

Produk dari pengabdian ini adalah papan komposit dengan ukuran standar papan kayu yaitu $2 \mathrm{~cm}$ x $20 \mathrm{~cm}$ x $60 \mathrm{~cm}$ mengikuti cetakan komposit. Meski demikian sejumlah produk papan komposit bisa diproduksi dengan cetakan berbeda antara lain seperti treng, kaso, dan balok. Hasil pembuatan papan komposit lalu diinformasikan ke mitra dalam hal ini Azmi dan Zainuddin selaku pengusaha pertukangan kayu di Batu Ringgit, Kelurahan Karang Pule, (lihat Gambar 4).
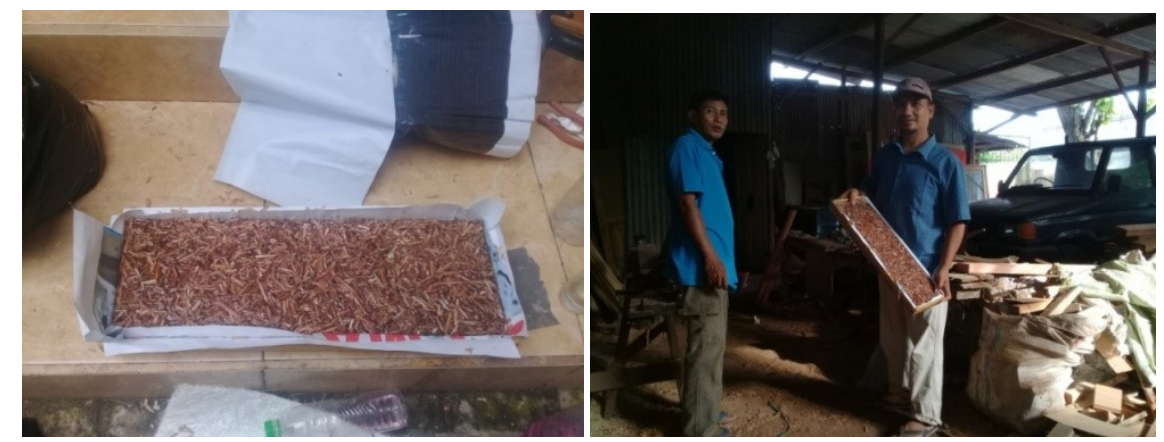

Gambar 3. Papan komposit yang dikeringkan diinfokan ke mitra. 

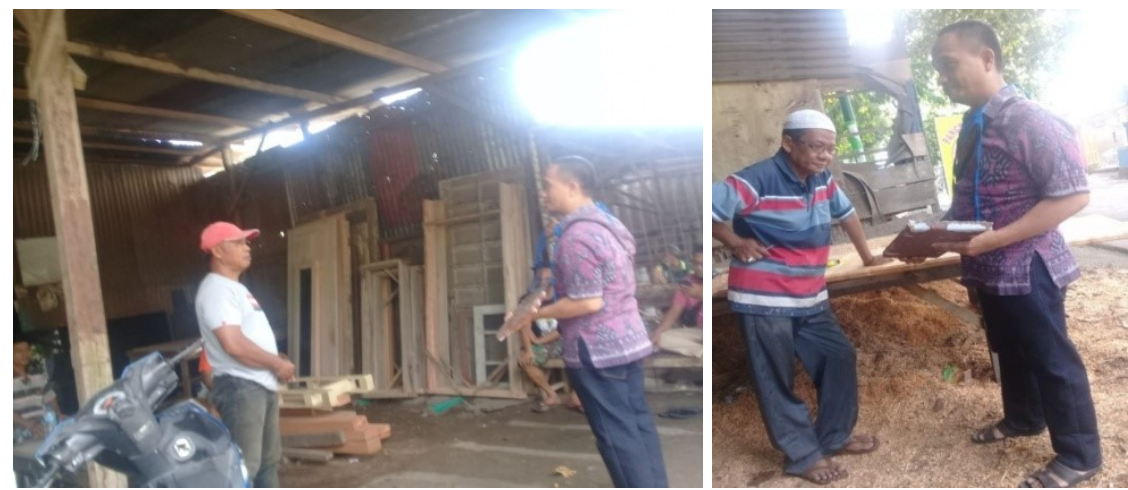

Gambar 4. Kegiatan penyuluhan depan ketua RT dan Zainuddin di Lingkungn Batu Ringgit.

Penyuluhan dilakukan tanggal 17 Desember 2020. Mitra memberikan respon positif dalam bentuk perhatian ke penyuluh dan mengakui kelebihan dari papan komposit tersebut. Karena komposit tersebut tidak lapuk apabila terkena air tidak seperti papan sintetis lain yang ada di pasaran yang rentang terhadap kelembaban atau lingkungan basah.

Karena itulah mitra menyambut positif adanya papan komposit ini hanya saja terkendala biaya pembelian epoxi sebagai bahan utama pengikat serbuk kayu dalam papan komposit.

\section{KESIMPULAN DAN SARAN}

Salah satu bentuk pemanfaatan serbuk kayu yang cocok adalah dengan mengolahnya menjadi bahan baku berupa papan atau balok komposit yang memiliki kekuatan yang sama dengan papan asli.

Dalam kegiatan pengabdian ini dihasilkan produk berupa papan komposit yaitu $2 \mathrm{~cm} \mathrm{x}$ $20 \mathrm{~cm}$ x $60 \mathrm{~cm}$ mengikuti cetakan komposit. Hasil pembuatan papan komposit tersebut selanjutnya diinformasikan ke mitra dalam bentuk melakukan penyuluhan langsung ke para mitra. Hasilnya mitra sangat antusias meski demikian mereka terkendala biaya pengadaan bahan resin sebagai penguat pada pembuatan papan komposit. Sarannya adalah mitr kerja perlu diberikan peralatan awal untuk memberikan semangat membuat langsung papan komposit.

\section{UCAPAN TERIMA KASIH}

Ucapan terimakasih kami tujukan ke semua pihak yang telah membantu terselenggaranya kegiatan ini terutama ke mitra usaha Pak Azmi dn Pak Zainuddin.

\section{DAFTAR PUSTAKA}

[1] "BPS Provinsi NTB No. 07/02/52/Th.VI, 2 November 2016, NTB Dalam Data, BPS NTB."

[2] Lombok Post, Surat Kabar Cetak, Usaha Petugas Kehutanan NTB Dalam Menangani Pembalakan Liar, 12 Desember 2016. .

[3] "Febriyanto, S., 2011. Penggunaan Metode Vacuum assisted Resin Infussion Pada Bahan Uji Komposit Sandwich Untuk Aplikasi Kapal Bersayap WISE-8, Tesis, FMIPA, Universitas Indonesia."

[4] "Gibson, R. F., 1994. Principle of Composite Material Mechanics, McGraw-Hill, New York."

[5] "Mahmuda, E., 2013. Pengaruh Panjang Serat Terhadap Kekuatan Tarik Komposit Berpenguat Serat Ijuk dengan Matrik Epoxy, Jurnal FEMA vo.1, No.3, p.79-84."

[6] "Setyawati, D., 2003. Sifat Fisis dan Mekanis Komposit Serbuk Kayu Plastik 
Polipropilena Daur Ulang. [Thesis]. Program Pascasarjana Institut Pertanian Bogor. Bogor (tidak dipublikasikan)."

[7] "Rusmiyatno, 2007. Pengaruh Fraksi Volume Serat Terhadap Kekuatan Tarik Dan Kekuatan Bending Komposit Nylon/Epoxy Resin Serat Pendek Random, Universitas Negri Semarang, Jurnal Struktur, 1 (2), hal. 23-28." 